\title{
WORK FROM HOME BY OCCUPATION IN ROMANIA: INITIAL ASSESMENT IN THE CONTEXT OF COVID-19 PANDEMIC
}

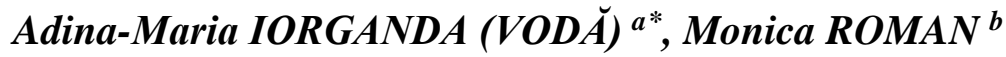 \\ ${ }^{a},{ }^{b}$ Bucharest University of Economic Studies, Romania
}

DOI: $10.24818 / \mathrm{IMC} / 2020 / 04.12$

\begin{abstract}
In the context of Covid-19 pandemic that accelerated the transition towards working from home, a question was raised worldwide: how many and what jobs are amenable to working from home? We analyze the literature and available quantitative and qualitative data to understand the characteristics of working from home in Romania. We assess the occupations in the Classification of Occupations in Romania (COR) to see how many are amenable to working from home and merge the results with the available statistical data regarding the employed population in Romania in 2019 by COR occupation groups. We estimate that 46\% of the Romanian COR occupations are amenable to working from home, while 1,7 million Romanian employees can perform home-based work. We acknowledge that jobs that could be performed remotely in Romania require at least a college degree, as they are found in the COR occupational groups specific to employees with tertiary education.
\end{abstract}

KEYWORDS: employment, labour market impact, occupations, telecommuting, work from home.

\section{INTRODUCTION}

COVID-19 is changing labour market outcomes worldwide, forcing a rapid change in working habits. The pandemic accelerated the automation of the labour market, unleashing to a great extend the extraordinary potential of teleworking. As Bloom shows (2020), workers may decide to work at home to reduce the probability of becoming infected as a result of interactions. Demand-side employment effects also emerge as vulnerable firms with little cash-on-hand adjust their staffing temporarily or permanently in response to shocks to demand their goods or services. In high, middle, and low-income countries, the COVID-19 outbreak has sparked deep concerns about the effects of the pandemic shock on employment. Multiple ways in which the COVID-19 crisis is changing the labour market are being debated, but four more prominent effects are being widely discussed (Autor and Reynolds, 2020): (1) telepresence, (2) de-densification in urban areas, (3) reallocation of sales and value-added towards large firms and (4) automation forcing.

Considering that telepresence is due to disrupt the management practices of the firms, and the probability of jobs loss during Covid-19 pandemic depends on the tasks that can be done at home (Adams-Prassl et al., 2020) some legitimate question emerges: how many jobs can be done from home and what jobs and from what economic sectors are more amenable to home-based work? Therefore, this paper aims to find responses to the questions raised above and present fresh

\footnotetext{
* Corresponding author. E-mail address: adinamvoda@yahoo.co.uk
} 
evidence regarding jobs that can be done from home in Romania, also contextualizing the information available for both advanced and developing countries.

We aim to investigate what type of jobs and how many of them can be performed from home in Romania, especially in the context of Covid-19 pandemic. We fill the gap in the existing literature by exploring how remote work penetrated certain occupations in Romania. The policy implications for the future are explored, especially regarding the extend remote work will continue after the pandemic ends.

\section{WHAT JOBS CAN BE DONE FROM HOME? A BRIEF LITERATURE REVIEW}

Many employees, perhaps with significant family responsibilities have always dreamt of working from home as much as possible. Apparently, for the most advantaged of them, the Covid-19 pandemic made their dream come true. Whereas working from home is desirable and more sustainable, especially in terms of impacts on the environment, and from a work-life balance perspective, still a certain number of characteristics could predict a job to be suitable to be performed remotely, especially from home, including those mediated by ITC instruments and communication channels (Dingel, 2020; Bartik, 2020; Hatayama, 2020): (1) results-based work, (2) less physical intensity or manual work (3) indoor work, (4) no supervision of interaction with public needed (less F2F-intensive), (5) no need to wear protective equipment and (6) no need to repair, maintain or inspect mechanical or electronic equipment, structures or materials (7) having an Internet connection at home. We would also add to these categories the digital skills of the populations. Recent research shows that certain types of jobs are amenable to work from home than others, especially jobs that are typically more well paid (Dingel and Neiman 2020) or jobs requiring tertiary education or more. Hence, more educated people are more prone to flexible jobs performed from home (Mas and Pallais, 2019) or are more willing to opt for work from home (Bartik et al. 2020).

Usually, 'gig jobs' and jobs for managers, people working in ITC sector, finance, consultancy, scientific and professional services, law, national and local government, and even educators are more amenable for work from home, as they showcase many of the characteristics mentioned above. Dingel and Neiman (2020) recently demonstrated that there is a strong correlation between wage level and the possibility to work from home, as 37 percent of American jobs that can be done at home account for 46 percent of the country's wages. Dias et al. (2020) evidenced the fact that this assumption has also been proved in the United Kingdom. As wage level is usually linked to education level, education is also a strong determinant of the ability to work from home.

On the other hand, people that cannot work from home also share a certain number of characteristics. For instance, in the US, they are low-income earners, are missing a college degree, do not have health insurance and usually rent their dwellings (Dingel and Neiman, 2020). Jobs for people working in sales, hotels and restaurants, personal and health care, farming, manufacturing, construction, food preparation and cleaning and maintenance are also not fit for work from home (Dingel and Neiman, 2020). Of course, the situation varies significantly between various regions of the country and between rural and urban or metropolitan areas, as lagging regions within one country have less amenable jobs to work from home (Sanchez et al., 2020). Younger employees 
(age 15-24) seem to be excessively affected by the pandemic as they are one category less likely to work from home, compared to older ones across the country (Sanchez et al., 2020). Nevertheless, the older ones are more likely to have severe forms of Covid-19, it is the younger people who bear the highest economic risk in the Covid-19 pandemic.

Gender might have some explanatory power when analyzing jobs that could be performed from home, but the situation varies greatly around the world. Indeed, women are more prone to wear the family burden of the lockdown because of schools and care centers shut down, meaning more childcare responsibilities, which translates into more work from home needs.

We should differentiate, in the context of Covid-19 pandemic, between jobs that can be performed entirely from home and jobs that can be performed most of the time from home. According to Mas and Pallais findings (2020), jobs with 80 percent of work that can be performed from home can be found in occupations such as computer and mathematics, personal care and services, arts, design, entertainment, sports, and media, business and financial operations, management and even community and social service.

Whatsoever, important challenges have been faced by various industries when being forced to shift to work from home for most of their employees. Feasibility constraints towards work from home as well as Internet access are a reliable predictor of the industries transitioning towards remote work (Sanchez et al., 2020).

As much as 1 in 5 jobs across the globe can be done from home. In low-income countries, the ratio is 1 in 26, whereas high-income countries, the ratio is 1 in 3 (World Bank, 2020). Internet access is a great predictor of the jobs that can be done from home (Sanchez et al., 2020).

Indeed, technology is a great enabler of remote interaction. Be it Zoom, phone, WhatsUp, Viver, Skype, e-mail or Webex communication channel, better connectivity for staff working from home (broadband and mobile internet) is a must when analyzing remote working. There are some efficiency gains from the use of technologies for remote interaction: faster interaction with clients available for virtual clients, increase frequency of communication, more fluid interactions, increase the availability of team members or business partners across regions, cost-saving, allowing to invest more time or engage more experts or deliver better quality, and the most important one: reduction of travel time, leading to a lower ecological footprint. Indeed, work-life balance benefits from reduced travel but suffered a lack of boundaries between 'work' and 'life'.

Overall, telecommutable jobs are safer, as job loss probability is depending on tasks that can be done from home (Adams-Prassl et al., 2020).

\section{DATA AND METHODOLOGY FOR THE ANALYSIS}

We use various data sources to showcase and estimate the working from home (WFH) jobs capacity in Romania and worldwide. First, we use EUROSTAT data regarding working from home in Europe and Romania, internet and broadband coverage and digital skills level. Second, we use Eurofound (b2020) survey data regarding the share of employees working from home in July 2020. It is representative of working from home during Covid-19 crisis for countries in the European Union (EU). We complement these findings with the results of other surveys in the United Kingdom (Taylor and Griffith, 2020) and Germany (Alipour et al., 2020). Thirdly, we use Dingel \& 
Neimans (2020) data and assessment of jobs that can be done at home, based on the US task content of a job. We acknowledge that the caveat of the analysis is that there are some differences regarding the task content of occupation around countries, as the analysis is done based on ONET database which is specific to the United States.

We run a qualitative analysis of the occupations that can be done from home in Romania using the Classification of Occupations in Romania (COR) database (developed based on the International Standard Classification of Occupations - ISCO 08). COR is a legal classification managed by the Ministry of Labor and Social Protection in Romania, which defines the six digit codes assigned to each job position, with job positions clustered by occupational sectors. It is mandatory for each employee in Romania to be assigned a COR code, as it is also included in the employment contract. As the number of new occupations is constantly increasing, the COR is periodically reviewed and amended. In its current version it covers 4329 occupations (https://mmuncii.ro/j33/index.php/ro/2014-domenii/munca/c-o-r).

Following a qualitative design, we extract manually and individually analyzed each COR occupation. A total number of 4329 occupations were analyzed, for assessing the potential of occupations that can be done at home, fully or partially. We rely on the COR descriptors of each occupational group and sub-group. Therefore, we have used the following criteria depicted from similar analysis (Dingel and Neiman, 2020), respectively: the capacity of a specific occupation to be performed from home (i) over the internet or (ii) by using an electronic device or (iii) by using portable equipment or instruments (such as brushes, etc).

In the final step of the research, we use the most recent data regarding the occupied population in Romania provided by the National Statistical Institute (NSI) at the level of each COR occupational group in 2019. We estimate the number of employees that could work from home, totally or partially, by each COR occupation group.

\section{THE GLOBAL COVERAGE OF REMOTE WORK AND THE COVID-19PANDEMIC}

As already discussed above, employees with higher education and good internet access have the highest chances to work in telecommutable occupations, therefore are less prone to job losses. Furthermore, this is usually the situation in high-income countries or upper-middle-income countries. On the other hand, poorer countries are 'doubly disadvantaged' (Sanchez et al., 2020), as there are fewer jobs that are potentially telecommutable and face more considerable ITC constraints.

Real-time surveys are used to measure in real-time the capacity and the effectiveness of working from home. For instance, almost half of the respondents participating in a survey in the US acknowledged they were working from home in the first week of April 2020 (Brinjolfsson et al., 2020), while 35\% respondents were doing the same in May 2020 (Bick et al., 2020). In the United Kingdom, for instance, in May 2020, 37 percent of firms reported having employees working from home, especially in higher productivity service industries, such as information and communication, real estate, finance and insurance, professional and scientific and administrative and support 
(https://www.coronavirusandtheeconomy.com/question/who-can-work-home-and-how-does-itaffect-their-productivity; https://decisionmakerpanel.co.uk/data/).

In Germany, 56 percent of jobs are amenable to full-time or part-time work from home. These jobs tend to be performed by high-skilled workers, are located mainly in urban areas, and are PCintensive tasks (Alipour et al., 2020).

In the EU, 4 in 10 employees started teleworking from home in the Covid-19pandemic, which amounts to almost 37 percent, according to a survey run by the Eurofound in April 2020. Most of the teleworking employees are from Finland (60\%), Luxembourg and Benelux countries (more than $50 \%$ ), and Italy, Austria and Ireland (more than 40\%). The working time of those who started to work from home during the pandemic remained almost unchanged. If we consider that approximately $10 \%$ of the EU citizens used to work from home daily before the pandemic, we observe that the pandemic brought abrupt change to the teleworking environment, the numbers of teleworkers tripled afterwards, as 37\% of EU 27 individuals declared working from home in April 2020 during the Covid-19 lockdown.

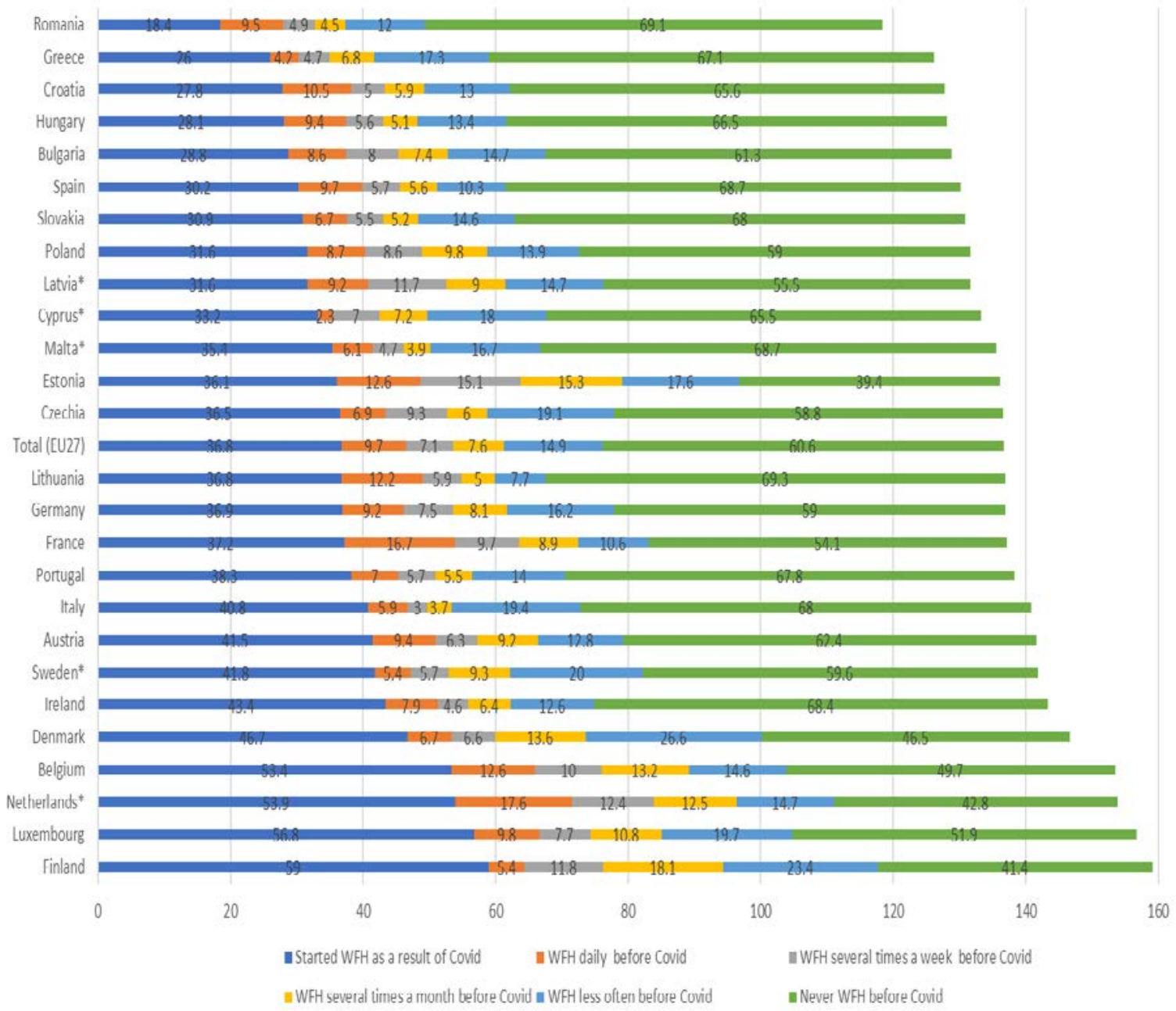

Figure 1. Number of employees working from home, 2020

Source: Authors calculation based on Eurofound data, July 2020

(https://www.eurofound.europa.eu/data/Covid-19-19/working-teleworking) 
Gender is a differentiating factor when analyzing which jobs are more amenable to working from home than others. In Europe, women are more likely to work from home than men, whereas in India there is no difference between the two categories. In contrast, in Turkey, women are less likely to work from home than men (Sanchez et al., 2020), probably because of the traditional occupations done by women versus men.

\section{THE ASSESMENT OF THE COVERAGE OF WORK FROM HOME IN ROMANIA}

Pre-Covid-19 evidence regarding teleworking shows that Romanians were the most numerous employees in the EU never tele-worked $(69,1 \%)$. Also, the Romanians were the last in the EU to work from home in various frequencies (bEurofound, 2020). The situation might be explicated by the fact that Romania has rather young legislation regarding teleworking (the majority of jobs that can be performed remotely are teleworkable), as Law number 88/2018 regarding teleworking activities was adopted recently, in 2018. The penetration of telework activities was small even at the level of white-collar jobs, only employees working in international corporations having that possibility. On the other hand, Romania has the lowest number of college degree workers in the EU, and, as we have seen in the previous chapter, that situation could reflect the fact that many jobs are not amenable for working from home, as we can also depict from the analysis presented below. Last but not least, the situation could be explained by the fact that Romanians were in 2019 the Europeans with the lowest level of digital skills, respectively 31\%, compared to an EU 28 average of $58 \%$.

According to Eurostat, only $0.8 \%$ of the Romanian employees used to work from home last year, representing almost 45.000 individuals, one of the lowest figures in the EU, when compared to $5.5 \%$ of the employees in other EU 28 Member States.

The Covid-19 lockdown might have accelerated the phenomena. However, even in that case, only 2 in 10 Romanian used to work from home in April 2020 during the Covid-19 lockdown, as Eurofound survey data suggests (bEurofound, 2020): the lowest number in the EU. It is worth to mention that according to a survey run during Covid-19 lockdown by BestJobs, one of the largest online recruitment platforms in Romania, approximately 29\% of employees acknowledged that they were working from home in the second part of March 2020 (BestJobs https://www.businessmagazin.ro/actualitate/cati-angajati-romani-lucreaza-de-acasa-si-cat-timpcred-ei-ca-vor-mai-petrece-izolati-la-domiciliu-19042334, 2020).

Dingel analysis showcase that in 2018 Romania ranks 55 places out of 86 states worldwide regarding the capacity to telework, with a $0.22 \%$ coefficient. Though the analysis is one of the reference documents in the field of teleworking capacity assessments, the caveat of the analysis is that it's not relevant for the European occupations, as it relies on the US ONET occupations database.

To overcome these possible biases, we analyzed the Romanian occupations amenable fully or partially to working from home, based on the COR. In order to assess the home-based working capacity of the occupations, we have used the criteria already mentioned in the literature review such as the capacity of a specific occupation to be performed fully or partially from home over the internet or using an electronic device (laptop, tablet, smartphone), or by using portable equipment or instruments (such as brushes, etc.). 
Table 1. Occupations amenable to working from home (WFH) in Romania

\begin{tabular}{|l|l|c|c|c|c|}
\hline \multicolumn{1}{|c|}{$\begin{array}{c}\text { COR Group } \\
\text { occupations }\end{array}$} & $\begin{array}{c}\text { COR } \\
\text { Group } \\
\text { occupations } \\
\text { (No) }\end{array}$ & $\begin{array}{c}\text { The occupied } \\
\text { population in } \\
\text { 2019 } \\
\text { (persons) }\end{array}$ & $\begin{array}{c}\text { WFH COR } \\
\text { occupations } \\
\text { (\%) }\end{array}$ & $\begin{array}{c}\text { Occupied } \\
\text { population that } \\
\text { could WFH } \\
\text { (persons) }\end{array}$ \\
\hline 1 & Managers & 1 & $182,315.00$ & 0.77 & $140,671.11$ \\
\hline 2 & Professionals & 2 & $1,350,202.00$ & 0.94 & $1,268,082.22$ \\
\hline 3 & $\begin{array}{l}\text { Technicians and associate } \\
\text { professionals }\end{array}$ & 3 & $553,083.00$ & 0.31 & $171,316.59$ \\
\hline 4 & Clerical support workers & 4 & $364,513.00$ & 0.27 & $98,813.77$ \\
\hline 5 & Service and sales workers & 5 & $1,323,091.00$ & 0.03 & $40,338.14$ \\
\hline 6 & $\begin{array}{l}\text { Skilled agricultural, } \\
\text { forestry and fishery } \\
\text { workers }\end{array}$ & 6 & $1,567,386.00$ & 0.00 & 0.00 \\
\hline 7 & $\begin{array}{l}\text { Craft and related trades } \\
\text { workers }\end{array}$ & 7 & $1,400,498.00$ & 0.00 & 0.00 \\
\hline 8 & $\begin{array}{l}\text { Other categories of } \\
\text { occupations }\end{array}$ & 8 & $1,939,235.00$ & 0.00 & 0.00 \\
\hline 9 & Elementary occupations & 9 & $844,920.00$ & 0.00 & 0.00 \\
\hline & Total: & & $\mathbf{9 , 5 2 5 , 2 4 3 . 0 0}$ & & $\mathbf{1 , 7 1 9 , 2 2 1 . 8 2}$ \\
\hline
\end{tabular}

Source: Authors own calculations of WFH percent based on the assessment of occupations that can be performed from home. Romanian NSI data available for 2019 regarding the employed population-based on occupations

(AMG110U - AMIGO - Employment by groups of occupations, by age group and by sex)

Overall, we find in our analysis that approximately 46\% of Romanian COR occupations are amenable totally or partially to be performed from home. In absolute numbers, approximately 2004 out of 4329 occupations are amenable to working from home, representing almost half of the total number of occupations. The amenability of working from home varies significantly between occupational groups, depending on the task content of the occupation performed fully or partially from home.

Jobs holding tasks that require permanent face-to-face (F2F) interaction, or intensive manual or repetitive tasks performed in a specific environment out of one's house, or tasks regarding the operation, handling, controlling, supervising or inspecting machinery or equipment in external/specific environment are not amenable to working from home. And this explains why there are no (or very few) occupations that could be performed from home at the level of five COR occupational groups, such as: 5 - Service and sales workers (164 occupations totally), 6 - Skilled agricultural, forestry and fishery workers (64 occupations totally), 7 - Craft and related trades workers (648 occupations totally), 8 - Other categories of occupations, such as plant and machine operators and machine and equipment assemblers (598 occupations totally) and 9 - Elementary occupations, such as unskilled workers, housekeepers, caretakers etc (82 occupations totally). The great majority of these occupations are for blue-collar occupants, requiring no or secondary education.

At the opposite end, we observe that tertiary education occupations holding tasks that could be performed partially or totally remotely by using electronic devices or portable equipment as they don't require physical presence in a certain environment or permanent F2F interactions are to be found in the first four COR occupational groups: 1 - Managers (127 out of 556 occupations are not amenable to working from home), 2 - Professionals (88 out of 1414 occupations are not amenable 
to working from home), 3 - Technicians and associate professionals (636 occupations) and 4 Clerical support workers (166 occupations). The Covid - 19 pandemics with its social distancing rules and the need to keep staff and patients safe along with the proliferation of telemedicine as a result (Jackson, 2020) showcased that also physicians' occupations (found in the COR professionals' occupational group) are partially amenable to hybrid home-based work, when not requiring physical presence for F2F interactions with the patient (Jackson, 2020). Consequently, physicians' practices hold various degrees of work-from-home capabilities, for instance imagistic doctors can telework $100 \%$ from home to interpret images sent by imagistic technicians that interact F2F with the patient, whereas front-line-emergency doctors cannot perform such a profession remotely.

The results confirm that also in the case of Romania white-collar jobs, requiring college education or higher (dominant in occupational group 1-4) are more amenable to working from home than others. The professional occupation group requiring tertiary education shows a $94 \%$ capacity to be conducted from home, whereas, at the opposite end, occupations such as crafting and trade workers, as well as elementary occupations deploying manual work in a certain environment are not at all amenable to working from home, as showcased in Table 1. Consequently, white-collar jobs occupants holding a tertiary education are also more likely to work from home than blue-collar jobs occupants.

Based on our assessment, we roughly estimate that approximately 1,7 million Romanian employees can work from home, considering the number of occupations that can be performed from home at the level of the each COR occupational group and the available statistical data regarding the employed population for each COR occupations group in 2019.

Considering that the COR covers occupations that are outdated or that are no longer performed (such as typist) due to economic and technical advancements, the final figures presented above might be biased to some extent. In order to have a better image of the reality, we will have to crosscheck this data with the Labour Inspectorate Revisal database when data is available. Also, the assessment of occupations amenable to working from home needs to be checked against administrative databases that provide information regarding working contracts that encompass working from home provisions.

Going forward, it is worth mentioning that according to Eurostat data, in 2019 Romania was above the EU average regarding broadband connectivity, but laid behind the $89 \%$ EU28 average regarding the proportion of households with broadband access $(82 \%)$, as this is one enabler of remote working.

Another enabler of the work from home amenability of jobs that seems not to be approached by the prominent researchers in the field is the level of digital skills of the population. As it can be observed, the low level of teleworking activities in Romania is substantiated by the low level of digital skills of the population. Considering that the greatest majority of jobs amenable to working from home is made of teleworkable jobs, the low level of Romanians' digital skills could explain why we see a concentration of working populations in jobs that are not amenable to remote work.

The novel analysis shows that in a developing country such as Romania a small share of the labor force respectively only 18\% (1.7 million) is covering jobs allowing for WFH.

The implications of these results should be read in the context of the future developments of work from home in the context of COVOD-19 pandemic. The economic implications in Romania are already severe, as some economic sectors such as tourism face reduction of personnel. Therefore, it is crucial knowing how much of the labor force may be at risk, in the context of a prolonged pandemic. In such a context, work from home may reduce forced unemployment due to a potential lockdown. 
The probability of remote work to continue after the Covid-19 pandemic is dependent on several factors, including productivity. In the future, potential productivity gains will be carefully weighed against the importance employees attribute to working from home (Mas and Pallais, 2019), especially for their work-life balance. Early evidence shows that many firms are less productive as a result of work from home (Bartik, 2019), but also that the Covid-19 crisis forced the transition to remote work will have a persistent impact on the future of work, while work from home will still showcase high level even after the crisis ends.

Even it is a little bit early to conclude over the subject, considering that the pandemic is far from an end, various firms' surveys conducted worldwide point to the fact that many employers expect their employees will work from home after the crisis ends. For instance, in the US, approximately 40 per cent of the questioned firms believe that $40 \%$ of their employee will continue to work from home in the future (Barti, 2020). Four factors are estimated (Bloom, 2020) to drive a permanent work from home shift: (i) expectations, as work from home during the pandemic proved to be better than expected, (ii) stigma, as pre-Covid-19 negative stigma appear to have disappeared, (iii) time and capital investments in work from home during Covid-19 pandemic and (iv) social distancing that is expected to persist even after a vaccine will be made available.

In Romania, as well as in the other countries, seeing the forced behavioural shifts that the Covid-19 pandemic brought in working from home and especially teleworking habits, it is expected that the trend will continue. Moreover, teleworking is a great inclusion route and a second chance for people with disabilities entering the labour market (aEurofound, 2020), considering their capacity to reduce employment barriers. In the past, employers were not eager to use teleworking as a way to integrate people with disabilities better, but this might also change because of the pandemic, bringing even more people with disabilities that are teleworking on the labour market.

\section{CONCLUSIONS}

Bearing in mind the correlation between income level and work from home capacity, appears that developing economies or lagging regions are confronted with greater challenge when having to work from home during periods when social distancing is required (Dingel and Neiman, 2020).

Findings show there is a great difference between educated and less-educated workers when assessing jobs' amenability to home-based work. Considering that jobs loss is influenced to a greater extend by the capacity of the job to be done from home, which is also dependent on Internet access and population's digital skills, there becomes of great importance to foster technology adoption, thus leading to greater job protection, especially during Covid-19pandemic and beyond. Also, due to COVID-19, some professions may be wiped out entirely, and this may require new kind of interventions. Moreover, this needs to be regularly analyzed and appropriate measures adopted by governmental officials.

In the case of Romania, early evidence shows that there is great potential for increasing the number of people working from home, especially by increasing the education and digital skills level of the population, thus increasing their chances to better and more paid jobs (Adams-Prassl et al., 2020).

Our analysis shows that almost half (46\%) of the occupations in Romania are amenable to working from home, while a rather small proportion of the population (18\%), respectively 1,7 million individuals occupying those occupations could have worked from home in 2019. The analysis has to be continued, as this evidence needs to be checked against official registries of employees' occupations from the Labor Inspectorate Revisal database. Also, future analysis should concentrate on better understanding the influence of the digital skills levels of the population and the household broadband coverage on the amenability of jobs to be performed from home. 


\section{REFERENCES}

Adams-Prassl, A., Boneva, T., Golin, M. \& Rauh, C. (2020). Inequality in the impact of the coronavirus shock: Evidence from real-time surveys. IZA Institute of Labor Economics. Retrieved September 18, 2020 from http://ftp.iza.org/dp13183.pdf.

Alipour, J., V., Falck, O. \& Schüller, S. (2020). Germany's Capacities to Work from Home. Retrieved September 19, 2020 from https://www.cesifo.org/DocDL/cesifo1_wp8227.pdf.

Autor, D., Reynolds, E. (2020). The Nature of Work after the COVID Crisis: Too Few Low-Wage Jobs. The Hamilton project. Retrieved September 26 2020, from https://www.hamiltonproject.org/assets/files/AutorReynolds_LO_FINAL.pdf.

Bick, A., Blandin, A. \& Mertens, K. (2020). Work from Home After the COVID-19 Outbreak. Retrieved September 17, 2020, from https://www.dallasfed.org/-/media/documents /research/papers/2020/wp2017.pdf.

Bloom, N. (2020). The bright future of working from home. Retrieved September 19, 2020, from https://siepr.stanford.edu/research/publications/bright-future-working-home.

Dingel, J. \& Neiman, B. (2020). How Many Jobs Can be Done at Home? Retrieved September 19, 2020, from https://bfi.uchicago.edu/working-paper/how-many-jobs-can-be-done-at-home/.

Jackson, N., M. (2020). Working from home: Is it possible for physician practices?. Retrieved September 27, 2020 from https://www.medicaleconomics.com/view/working-home-it-possiblephysician-practices.

Mas, A. \& Pallais, A. (2019). Alternative Work Arrangements, Retrieved September 20, 2020, from https://scholar.harvard.edu/files/pallais/files/alternative_work_arrangements_01.pdf.

Ministry of Labor and Social Protection in Romania. Classification of Occupations in Romania. Retrieved September 19, 2020, from http://mmuncii.ro/j33/index.php/ro/2014domenii/munca/c-o-r?id=46:cor-isco-.

Sanchez, D., G., Parra, N., G., Ozden, C., Rijkers, B., Viollaz, M. \& Winkler, H. (2020). Who on Earth Can Work from Home? World Bank. Retrieved September 18, 2020, from http://documents1.worldbank.org/curated/en/225881596202941026/pdf/Who-on-Earth-CanWork-from-Home.pdf.

Taylor, K. \& Griffith, R. (2020). Who can work from home and how does it affect their productivity? Economics Observatory. Retrieved September 19, 2020, from https://www.coronavirusandtheeconomy.com/question/who-can-work-home-and-how-does-itaffect-their-productivity.

aEurofound (2020). How to use the surge in teleworking as a real chance to include people with disabilities? Retrieved September 21, 2020 from https://www.eurofound.europa.eu /publications/blog/how-to-use-the-surge-in-teleworking-as-a-real-chance-to-include-peoplewith-disabilities.

bEurofound (2020). E-survey data: Living, working and COVID-19. Retrieved September 21, 2020, from https://www.eurofound.europa.eu/data/covid-19/working-teleworking.

Matei, I. (2020, 02 Aprilie) Câţ̧i angajaţi români lucrează de acasă şi cât timp cred ei că vor mai petrece izolaţi la domiciliu. Retrieved Septenber 12, 2020 from https://www.businessmagazin.ro /actualitate/cati-angajati-romani-lucreaza-de-acasa-si-cat-timp-cred-ei-ca-vor-mai-petrece-izolati-ladomiciliu-19042334. 